\title{
Residency slots at teaching hospitals eyed for cutbacks
}

These are uncertain times for US teaching hospitals. Faced with increased competition from less-expensive community hospitals, potential cuts in government Medicare spending and cuts in federal funding for graduate medical education, teaching hospitals are restructuring. They are cutting staff or high-technology services, while emphasizing primary care, to meet market and budgetary demands. A shift towards care on an outpatient basis and towards health maintenance organizations (HMOs) or for-profit managed care corporations has provided additional pressures to cut costs.

Caught in the upheaval, residency programmes from Massachusetts to California are under scrutiny and facing cutbacks. Nationally, hospitals have a total of 22,000-25,000 first-year residency positions. That number is $40-50$ per cent greater than the $16,000-17,000$ graduates of US medical schools annually.

It has been difficult to reach a consensus about what to do. One choice would be to reduce the number of approved residency training positions, bringing it closer to the number of graduates from US schools. The alternative is to continue the practice of accepting large numbers of graduates of nonUS schools to fill the vacant residency slots.

Brigham and Women's Hospital and Massachusetts General Hospital (MGH), both in Boston, for example, have cut 5 per cent of their first-year residency slots for 1995-96, leaving a total of 320 first-year residency slots between the two hospitals. The cuts have spared primary-care residency positions. A second round of cuts at the two Harvard-affiliated hospitals could eliminate an additional 10 per cent of entry-level positions for 1996-97. Once again, primary care likely will be unaffected, but further reductions could cut beyond the first-year positions, says H. Richard Nesson, president of Brigham and Women's and chief executive officer of Partners HealthCare System of Boston, which oversees the recent consolidation between Brigham and Women's and MGH. "Undoubtedly, more residencies will be shared," says Nesson. (The two hospitals have a total of 1,200 residents and fellows.)

Hospital administrators at $\mathrm{MGH}$ were asked by Samuel $O$. Thier, president of the hospital, to draw up proposals for a 20 per cent cut in the overall number of residency positions over three to five years.

Other teaching hospitals are likely to fol-

\author{
IMAGE \\ UNAVAILABLE FOR \\ COPYRIGHT \\ REASONS
}

Massachusetts General: Cutting back on its first-year residency positions.

low suit. Detroit's Henry Ford Health System is considering cutbacks to its 650 residency slots, but the details are still under discussion. Duke Hospital in Durham, North Carolina, the principal teaching hospital for Duke University School of Medicine, now supports 497 total residencies. Dan Blazer, dean of medical education, anticipates a 30 per cent cut in the hospital's 900 residencies and fellowships. These cuts are part of a larger restructuring effort at Duke Hospital, leading to acrossthe-board cuts that will pare its overall size by 30 per cent.

A residency position costs Duke Hospital about $\$ 55,000$, Blazer says. Although education dollars come from various sources, "Medicare is a very heavy and extremely important component of paying residents' salaries in every hospital." Consequently, teaching hospitals are closely eyeing proposed legislation now under discussion in the US Congress that could cut $\$ 270$ billion from the Medicare programme between 1996 and 2002. Contributing about $\$ 6$ billion annually, Medicare's medical education payments help cover residents' salaries and benefits, corresponding administrative and teaching costs, and any additional hospital expenses incurred by referring patients to teaching hospitals.

The trend towards managed care such as HMOs may mean less need for physicians, particularly those in specialties and subspecialties, says Robert M. Politzer, chief of the Bureau of Health Professions' work force analysis and research branch. The bureau is a federal agency under the US Department of Health and Human Services. Politzer predicts that unless changes are made, the United States will have 140,000 more specialists than are needed by the year 2010, a number that he says will hold steady into 2020 , when there will also be 14,000 too few general physicians. Currently, Politzer says, residency programs ultimately produce 2.3 specialists for every one general physician. He suggests, however, that a 1:1 ratio is more appropriate, although the figure is much disputed.

Already, more medical graduates are moving into primary-care positions, notes Marvin Dunn, director of the division of graduate medical education at the American Medical Association, Chicago.

Cuts in government funding would not necessarily mean fewer residencies, Dunn says, but could mean that someone else would have to pay.

The Association of American Physicians and Surgeons believes that the government should not dictate the numbers and breakdown by discipline of residency programmes, says Jane M. Orient, executive director of the Tucson, Arizona-based association, which has 5,000 members. Instead, the public's own choices about medical care and the marketplace should determine which specialties are viable, she says. Orient views the trend away from specialists as part of a move towards a "dumbing-down" of the medical profession.

So far, the federal government has funded graduate medical education without stipulating physician numbers or specialties, says Kevin Grumbach of the University of California's Institute for Health Policy Studies and its Center for Health Professions. This lack of guidance, he says, has motivated 31 state legislatures to introduce bills that would require quotas.

California is one such state. The University of California's five medical schools and its hospital network collectively provide more than 4,000 residencies. Prompted in part by political demands, the University of California at San Francisco is completing plans to cut 30 per cent of its residency slots by the year 2001 , bringing the number of specialty and primary-care residency positions to 500 and 574 , respectively, says James O'Donnell, associate dean of postdoctoral education.

Medical graduates from overseas could also be affected by the cutbacks. Because of the abundance of first-year slots, graduates from overseas now fill 20 to 25 per cent of residency slots in the United States.

COLleEN M. SAuber

Boston 